\title{
Celecoxib regulates apoptosis and autophagy via the PI3K/Akt signaling pathway in SGC-7901 gastric cancer cells
}

\author{
MIN LIU $^{1 *}$, CHUN-MEI LI $^{2 *}$, ZHAO-FENG CHEN ${ }^{1}$, RI JI $^{1}$, QING-HONG GUO ${ }^{1}$, \\ QIANG LI $^{1}$, HONG-LING ZHANG ${ }^{1}$ and YONG-NING ZHOU ${ }^{1}$ \\ Divisions of ${ }^{1}$ Gastroenterology and Hepatology, ${ }^{2}$ Oncology, \\ The First Hospital of Lanzhou University, Lanzhou, Gansu 730000, P.R. China
}

Received November 30, 2013; Accepted March 20, 2014

DOI: 10.3892/ijmm.2014.1713

\begin{abstract}
Gastric cancer, one of the most common malignancies worldwide, typically has a poor prognosis and poor survival rate. Previous studies have investigated the chemopreventive effect of celecoxib. In the present study, the SGC-7901 human gastric cancer cell line was utilized to examine the chemopreventive mechanisms of celecoxib. The inhibition of cell proliferation was determined using MTT assay, cell apoptosis was monitored by terminal deoxynucleotidyl transferase-mediated dUTP nick end-labeling (TUNEL) and flow cytometry, and cell ultrastructural changes were assessed via transmission electron microscopy. The mRNA expression of Akt, caspase- 8 and -9 was examined using quantitative reverse-transcription-polymerase chain reaction (qRT-PCR) and p-Akt, procaspase-8 and -9 were analyzed via western blotting. The results showed that celecoxib inhibited the proliferation of SGC-7901 cells in a time- and dosedependent manner. Additionally, celecoxib induced apoptosis as substantiated by typical apoptotic bodies, autophagosomes and an increased apoptotic rate. It was found that following celecoxib treatment, Akt mRNA expression was not significantly altered, and that $\mathrm{p}$-Akt protein levels decreased in a time- and dose-dependent manner. Additionally, caspase- 8 and -9 mRNA expression was significantly increased, while procaspase- 8 and -9 protein expression decreased relative to the time- and dose-dependent effects. These results demonstrated that celecoxib induced apoptosis and autophagy of gastric cancer cells in vitro through the PI3K/Akt signaling pathway. Moreover, our findings suggested that celecoxib induces apoptosis in gastric cancer cells through the mitochondrial and death receptor pathways, providing additional
\end{abstract}

Correspondence to: Dr Yong-Ning Zhou, Division of Gastroenterology and Hepatology, The First Hospital of Lanzhou University, Lanzhou, Gansu 730000, P.R. China

E-mail: yongningzhou@sina.com.cn

${ }^{*}$ Contributed equally

Key words: apoptosis, autophagy, celecoxib, cyclooxygenase 2, Akt, caspase-8, caspase-9, gastric carcinoma understanding regarding the chemopreventive behaviors of celecoxib and its uses in cancer therapy.

\section{Introduction}

Gastric cancer is among the most common malignancies worldwide, with a 5-year survival rate of only $20 \%$ (1). Due to the fact that this type of cancer has a poor prognosis, attention has been drawn to the chemopreventive effect of celecoxib, a cyclooxygenase-2 (COX-2) inhibitor. COX, also known as prostaglandin synthase peroxidase, is the rate-limiting enzyme catalyzing arachidonic acid into prostaglandins, with COX-2 being involved in inflammatory diseases and certain types of tumor $(2,3)$. In vitro and in vivo studies have shown that the long-term and widespread use of non-steroidal anti-inflammatory drugs (NSAIDs) may contribute to the maintenance of gastric health, with epidemiological studies showing possible risk reduction $(4,5)$.

Apoptosis, programmed cell death (PCD), occurs in multicellular organisms, with autophagy also triggering PCD through different apoptotic mechanisms (6,7). Celecoxib and related compounds have been shown to induce cell cycle arrest, inhibit tumor growth and suppress tumor angiogenesis, with celecoxib potently inducing apoptosis in tumor cells (8-11). An increased expression of COX-2 and Akt in gastric carcinomas relative to normal gastric mucosa, with celecoxib treatment inducing tumor apoptosis has also been shown (12). Further experimentation showed that COX-2 inhibitors may induce apoptosis by affecting Akt phosphorylation, thus activating the Akt signaling pathway (13). In this study, we used the selective COX-2 inhibitor celecoxib to treat the SGC-7901 gastric cancer cells and to induce cell apoptosis in vitro. The effects of celecoxib on apoptotic and autophagic cell death through the monitoring of mRNA and protein levels of Akt, caspase- 8 and -9 were also examined. This approach aids in further characterization of the apoptotic effect of celecoxib via the PI3K/Akt signaling pathway in order to gain a better understanding of its antitumor effects.

\section{Materials and methods}

Cell culture. SGC-7901 human gastric cancer cells (Type Culture Collection Committee, Chinese Academy of Sciences, Shanghai, China) were cultured in RPMI-1640 medium (Gibco, 
Table I. Primer pairs for qRT-PCR.

\begin{tabular}{lllc}
\hline Gene name & \multicolumn{1}{c}{ Accession } & \multicolumn{1}{c}{ Sequence (5'-3') } & Product size (bp) \\
\hline Caspase-9 & NM_001229 & F: CCCATATGATCGAGGACATCCA & 186 \\
& & R: ACAACTTTGCTGCTTGCCTGTTAG & 83 \\
Caspase-8 & NM_001228 & F: GGTACATCCAGTCACTTTGCCAGA & 108 \\
Akt & R: GTTCACTTCAGTCAGGATGGTGAGA & 126 \\
$\beta$-actin & NM_005163 & F: GTGGCAGCACGTGTACGAGAA & \\
& & R: GTGATCATCTGGGCCGTGAA & \\
\hline
\end{tabular}

Long Island, NY, USA) with $2 \mathrm{mmol} / \mathrm{l}$ glutamine, supplemented with $10 \%$ fetal bovine serum (FBS; HyClone, Logan, UT, USA), $50 \mathrm{U} / \mathrm{ml}$ penicillin, and $50 \mathrm{mg} / \mathrm{ml}$ streptomycin. The cells were plated at a density of $1 \times 10^{5}$ cells $/ \mathrm{ml}$ in 6 -well tissue culture plates and grown to confluency at $37^{\circ} \mathrm{C}$ with $5 \% \mathrm{CO}_{2}$. When $50 \%$ confluency was reached, serum-supplemented medium was replaced with the recommended serum-free RPMI-1640 medium for overnight culturing before celecoxib intervention. Celecoxib, provided by the Faculty of Medicine, the Chinese University of Hong Kong, stock solution was added to the serum-supplemented medium at different concentrations and cultured until the detection time.

MTT assay. The inhibition of cell proliferation in SGC-7901 cells following celecoxib treatment was evaluated using an MTT assay (Sigma-Aldrich, Shanghai, China) as per the manufacturer's instructions. Briefly, $5 \times 10^{3}$ cells/well were seeded in 96-well plates, incubated in culture medium for $24 \mathrm{~h}$, and treated with varying concentrations of celecoxib $(0,50,75$, 100 and $125 \mu \mathrm{mol} / \mathrm{l}$ ) for 24,48 and $72 \mathrm{~h}$, with parallel samples treated with DMSO only serving as controls. Following treatment, the formation of formazan crystals was measured after $4 \mathrm{~h}$ of MTT incubation (10\% v/v) at an optical density (OD) of $490 \mathrm{~nm}$, with each experiment repeated in triplicate. The relative cell proliferation inhibition rate was calculated as: $\left(1-O D 490_{\text {Test }} / O D 490_{\text {Control }}\right) \times 100 \%$ to show a percentage value.

TUNEL assay. DNA breaks occur late in the apoptotic pathway and can be determined and analyzed by performing the TUNEL assay (Roche, Basel, Switzerland). Firstly, cells were seeded on coverslips and treated with $100 \mu \mathrm{mol} / 1$ celecoxib for $72 \mathrm{~h}$. Following treatment, the cells were washed, fixed and stained as per the manufacturer's instructions and apoptotic numbers evaluated using a confocal laser scanning microscope (Leica, Wetzlar, Germany) at 515-565 nm.

Flow cytometric (FCM) analysis of apoptosis. Apoptosis was assessed by flow cytometric analysis using the Annexin V-FITC/PI apoptosis detection kit (Invitrogen, Life Technologies Ltd., Carlsbad, CA, USA). SGC-7901 cells were seeded in 6 -well plates at $\sim 5 \times 10^{4}$ cells/well. Following treatment with celecoxib, the cells were trypsinized, centrifuged to remove the supernatant, washed with phosphate-buffered saline (PBS), suspended in $100 \mu \mathrm{l}$ of $1 \mathrm{X}$ binding buffer $(10 \mathrm{mM}$
HEPES, $140 \mathrm{mM} \mathrm{NaCl}$, and $2.5 \mathrm{mM} \mathrm{CaCl}_{2}$ ), and stained with Annexin $\mathrm{V}$ and PI as per the manufacturer's instructions. FITC-positive and PI-negative cells were considered apoptotic cells, PI-positive cells were considered necrotic, and unstained cells were considered normal viable cells. The apoptotic rates of the various cell groups were calculated and comparisons of apoptotic rates were conducted among the various groups.

Transmission electron microscope (TEM) analysis of cell ultrastructure. Cells were seeded on coverslips, treated with $125 \mu \mathrm{mol} / \mathrm{l}$ celecoxib for $72 \mathrm{~h}$ (with a parallel untreated control), cultured in RPMI-1640 for $72 \mathrm{~h}$, collected and fixed with $3 \%$ glutaraldehyde. The cells were washed with PBS, fixed in $1 \%$ osmium tetroxide, dehydrated by graded ethanol and acetone, and routinely embedded and polymerized. The slices were contrasted with an aqueous solution of uranyl acetate and lead citrate and examined by JEM-1230 transmission electron microscope (Jeol Ltd., Tokyo, Japan).

Quantitative reverse-transcription-polymerase chain reaction ( $q R T-P C R)$ analysis. SGC-7901 cells were cultured at a density of $1 \times 10^{5}$ cells $/ \mathrm{ml}$ in 6 -well tissue culture plates. One group was treated with various concentrations of celecoxib $(0,75,100$ and $125 \mu \mathrm{mol} / \mathrm{l})$ and cultured for $72 \mathrm{~h}$, while an additional test group was treated with $125 \mu \mathrm{mol} / 1$ celecoxib for $0,24,48$ and $72 \mathrm{~h}$. Total RNA was extracted by a column RNA extraction kit (Sangon, Shanghai, China) and reversetranscribed into cDNA at $37^{\circ} \mathrm{C}$ for $15 \mathrm{~min}$, and $85^{\circ} \mathrm{C}$ for $5 \mathrm{sec}$. Diluted cDNA was subjected to qRT-PCR using a SYBR ${ }^{\circledR}$ Premix Ex Taq ${ }^{\mathrm{TM}}$ II kit (Takara Bio, Inc., Shiga, Japan) in $25 \mu \mathrm{l}$ of reaction solution containing $2 \mu \mathrm{l}$ of cDNA template, $1 \mu \mathrm{M}$ of each primer, $10 \mu \mathrm{l}$ of $2 \mathrm{X}$ SYBR-Green master mix, and brought to the final volume with RNase-free water. Reactions were performed in triplicate via a PCR thermal cycler (RoterGene 3000; Corbett, Sydney, Australia) under the following conditions: pre-denaturation at $95^{\circ} \mathrm{C}$ for $30 \mathrm{sec}, 40$ cycles of denaturation at $95^{\circ} \mathrm{C}$ for $5 \mathrm{sec}$, and annealing at $62^{\circ} \mathrm{C}$ for $30 \mathrm{sec}$. The relative expression was calculated by the $2^{-\Delta \Delta \mathrm{CT}}$ formula. The primer pairs for qRT-PCR are listed in Table I.

Western blot analysis. Total protein was extracted and protein concentrations established via bicinchoninic acid (BCA) assay. Protein $(25 \mu \mathrm{g})$ was denatured, separated by SDS-PAGE electrophoresis and transferred to a PVDF membrane. After 


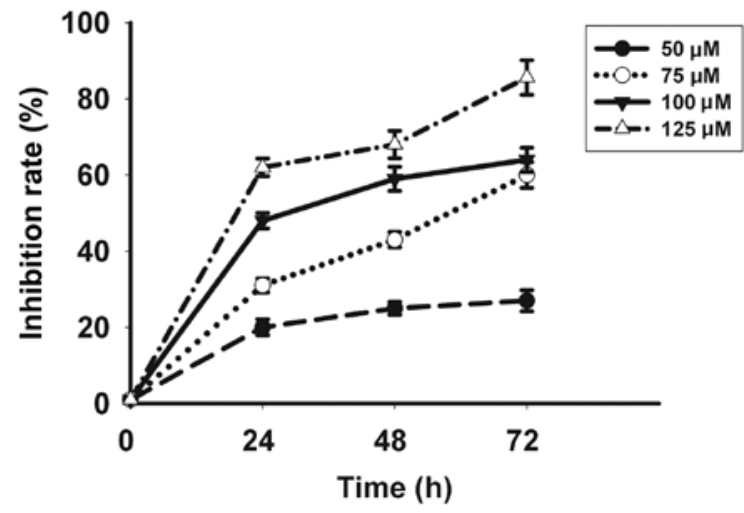

Figure 1. Inhibitory effects of celecoxib on cell proliferation of the SGC-7901 gastric cancer cell line detected by MTT analysis. Following treatment with celecoxib at the indicated concentrations and time-points, SGC-7901 cells showed a significant inhibition of cell proliferation in a time- and dose-dependent manner.

blocking overnight at $4^{\circ} \mathrm{C}$ using $5 \% \mathrm{BSA}$, the membranes were incubated with primary antibodies (anti-procaspase-8 1:2,500 and procaspase-9 1:2,000; both from Abcam, Cambridge, MA, USA), p-Akt 1:800 (Bioworld, St. Louis Park, MN, USA) for $2 \mathrm{~h}$ at room temperature, washed by TBST and incubated with the corresponding horseradish peroxidase (HRP)-conjugated secondary antibody at 1:2,000 dilution for $2 \mathrm{~h}$. Bands were visualized using enhanced chemiluminescence (ECL; Applygen, Beijing, China) detection reagents and scanned images were quantified using ImageJ software. Experiments were performed in triplicate with $\beta$-actin used as a housekeeping control for normalization. The ratio of target gene to $\beta$-actin was used for semi-quantification and comparison between different groups.

Statistical analysis. Triplicate data are presented as mean values and shown as the means \pm standard deviation (SD). Samples were analyzed by one-way ANOVA, with $\mathrm{P}<0.05$ considered to indicate statistical significance.

\section{Results}

Celecoxib inhibits proliferation of SGC-7901 cells. Following in vitro treatment with celecoxib, the SGC-7901 gastric cancer cell line showed a significant inhibition of cell proliferation in a time- and dose-dependent manner, with the most pronounced effect evident at a concentration of $125 \mu \mathrm{mol} / 1$ for $72 \mathrm{~h}$ as identified by a proliferation inhibition rate of $85.6 \pm 4.51 \%$ (Fig. 1).

Celecoxib induces apoptosis of SGC-7901 cells. Fluoresceinlabeled dUTP was connected to DNA 3'-OH ends of apoptotic cells by the deoxynucleotidyl transferase enzyme. Apoptotic cells with green fluorescence were detected by laser scanning confocal microscopy at an excitation of 515-565 nm, while all cells were exhibited as red under bright field microscopy. The two images were superimposed to show the specificity of apoptotic cells (yellow) and their position. Celecoxib-treated cells (Fig. 2B) showed significant levels of apoptosis relative to the control (Fig. 2A), with a statistical significance of $\mathrm{P}<0.05$.

Treatment with $0,75,100$ and $125 \mu \mathrm{mol} / 1$ of celecoxib for $72 \mathrm{~h}$ yielded apoptotic rates of $4.0 \pm 0.91,12.9 \pm 1.32,24.6 \pm 3.63$
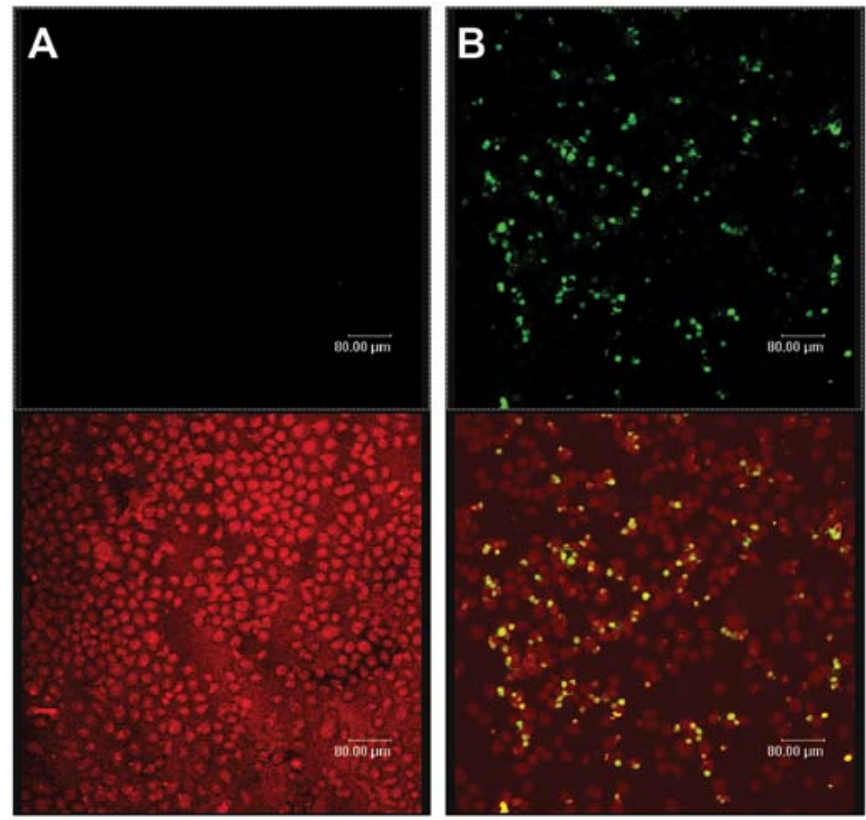

Figure 2. Apoptosis was assessed by terminal deoxynucleotidyl transferasemediated dUTP nick end-labeling (TUNEL) analysis for SGC-7901 human gastric cancer cells. (A) Control group; (B) group treated with $100 \mu \mathrm{mol} / 1$ celecoxib for $72 \mathrm{~h}$. The apoptotic cell number of the group treated with $100 \mu \mathrm{mol} / \mathrm{l}$ celecoxib for $72 \mathrm{~h}$ increased significantly relative to the control. Apoptotic cells with green fluorescence were detected by laser scanning confocal microscopy at an excitation of 515-565 $\mathrm{nm}$, while all the cells exhibit a red image under bright field microscopy. The two images were superimposed to show the specificity of apoptotic cells (yellow) and their position..

and $35.7 \pm 2.73 \%$, respectively, with a statistical significance of $\mathrm{P}<0.05$ when compared to the control group. Treatment with $125 \mu \mathrm{mol} / 1$ of celecoxib for $0,24,48$ and $72 \mathrm{~h}$, yielded apoptotic rates of $2.2 \pm 0.32,8.5 \pm 1.57,20.3 \pm 2.84$ and $35.7 \pm 2.73 \%$, respectively. Both study sets demonstrated a gradual increase in apoptotic rates in a time-and dose-dependent manner (Fig. 3).

Celecoxib alters the ultrastructure of SGC-7901 cells. Following treatment with $125 \mu \mathrm{mol} / 1$ celecoxib for $72 \mathrm{~h}$, typical early apoptotic changes were found to include nuclear membrane shrinkage and retraction (Fig. 4A), nuclear chromatin condensation, marginalization and crescents, with late apoptotic changes observed by nuclei cleavage into fragments and apoptotic body production (Fig. 4B). Additionally, typical autophagic structures were found to include several cytoplasmic autophagic vacuoles and autophagosomes, which swallowed organelles (Fig. 4C and D).

Effect of celecoxib on Akt, caspase-8 and -9 expression. No significant change in the mRNA levels of Akt was observed subsequent to treatment with celecoxib; however, the presence of p-Akt decreased in a time- and dose-dependent manner. Caspase- 8 mRNA expression increased in a dose-dependent manner at concentrations of 75, 100 and $125 \mu \mathrm{mol} / 1$ of celecoxib. Caspase-9 mRNA expression levels increased significantly at a concentration of 100 and $125 \mu \mathrm{mol} / 1$ of celecoxib (Fig. 5A). Following treatment with $125 \mu \mathrm{mol} / 1$ of celecoxib for 24,48 and $72 \mathrm{~h}$, caspase- 8 and -9 mRNA expression increased significantly (Fig. 5B). By contrast, procaspase- 8 and -9 protein expression was significantly 

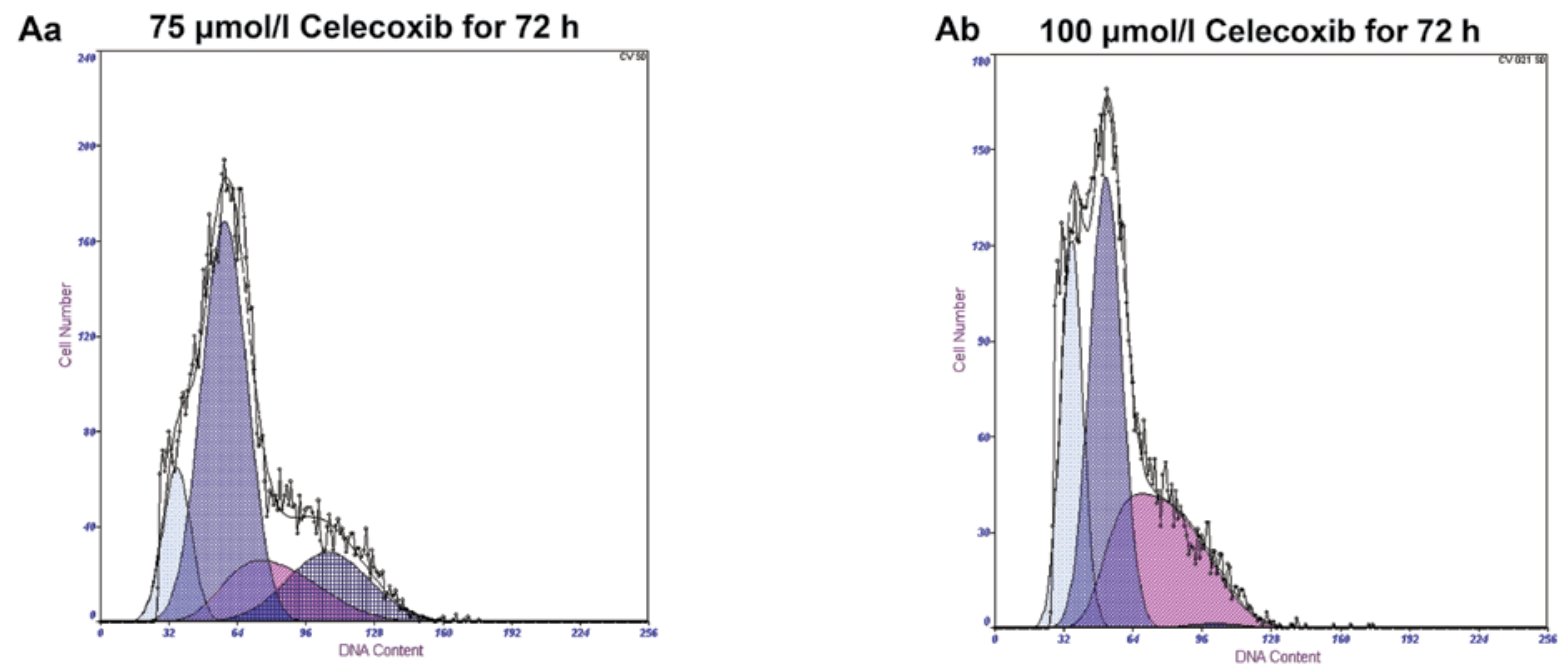

Ac $\quad 125 \mu \mathrm{mol} / \mathrm{l}$ Celecoxib for $72 \mathrm{~h}$
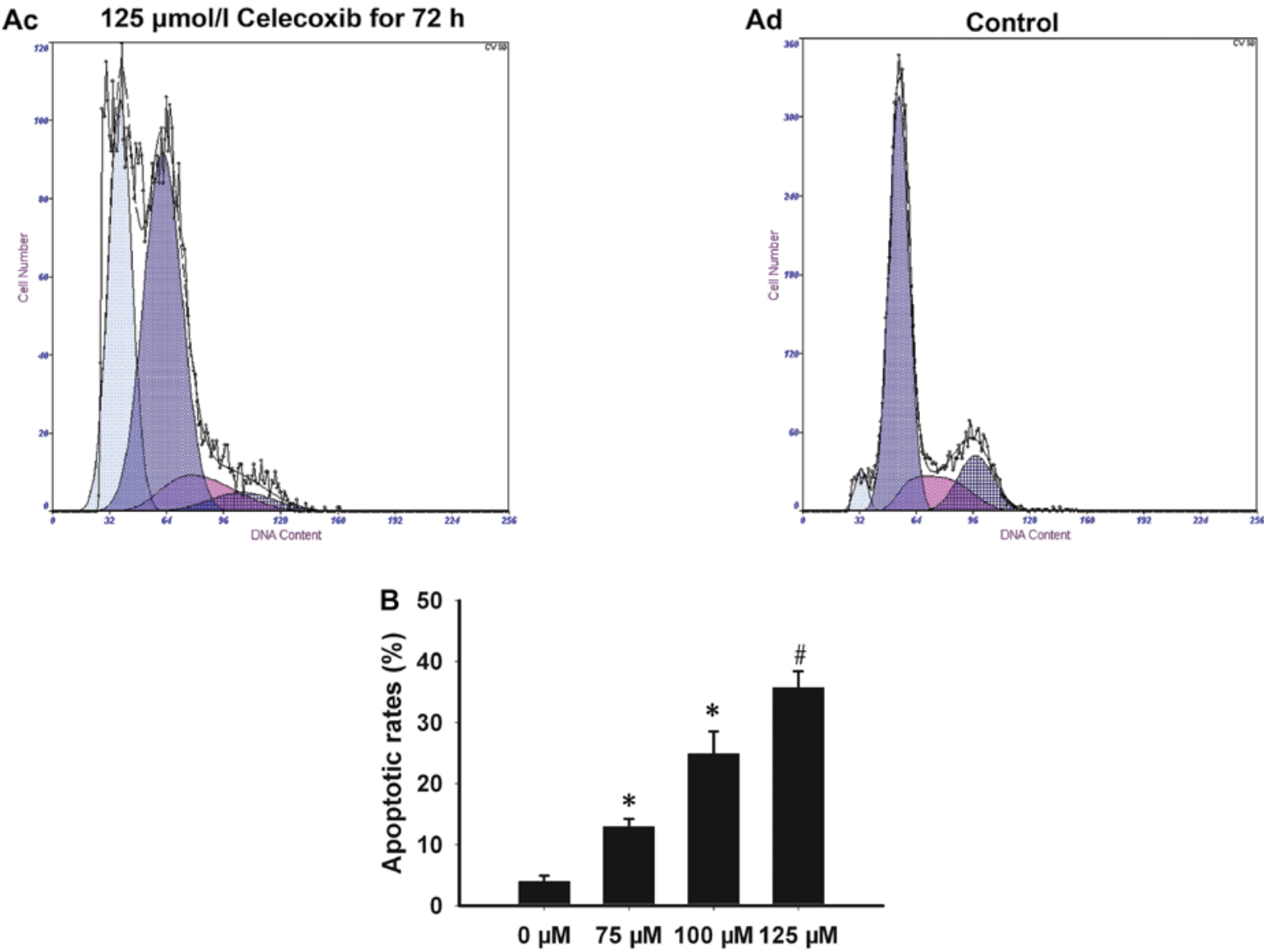

Figure 3. Apoptotic rates of human gastric cancer cell SGC-7901 after treatment with celecoxib at different doses and time-points as detected by flow cytometry. The apoptotic rates of SGC-7901 cells markedly increased in a time- and dose-dependent manner following treatment with $0,75,100$ and $125 \mu \mathrm{mol} / 1$ of celecoxib for $72 \mathrm{~h}$ (A and B) ${ }^{*} \mathrm{P}<0.05$ or ${ }^{\#} \mathrm{P}<0.01$ when compared with the control group..

lower than the control group in a time- and dose-dependent manner (Fig. 6). These results showed that celecoxib may inhibit Akt phosphorylation and promote caspase-8, -9 transcription and procaspase- $8,-9$ protein activation.

\section{Discussion}

Gastric carcinoma is among the most common malignancies worldwide, with an elevated 5-year postoperative mortality rate (14) thus creating a need for an alternative treatment method. Currently, the role of celecoxib, a non-cytotoxic COX-2 inhibitor, in cancer therapy has been under scrutiny (14). COX, also known as prostaglandin synthetase, has three known isoenzymes in mammals, COX-1, COX-2 and COX-3 (15). COX-2 is present at low levels of expression in most normal tissues, but tumor factors, inflammatory cytokines and growth factors could promote its expression (16). COX-2 is related to the development of tumors by promoting tumor 
$\mathrm{Ca}$

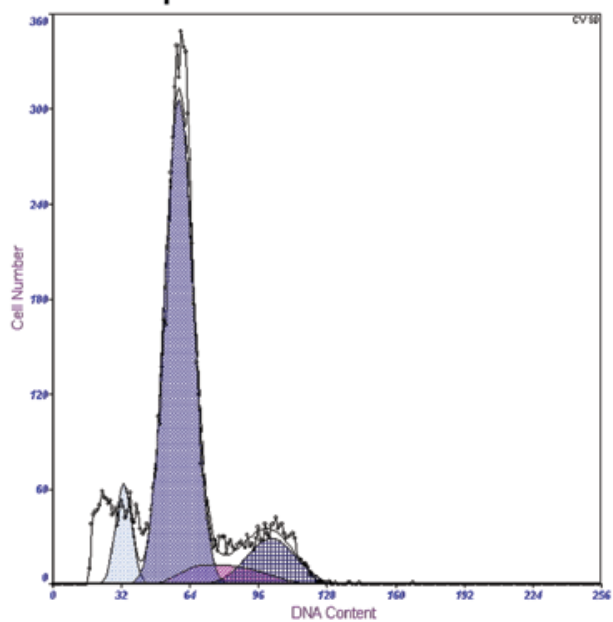

Cc $\quad 125 \mu \mathrm{mol} / / \mathrm{l}$ Celecoxib for $72 \mathrm{~h}$

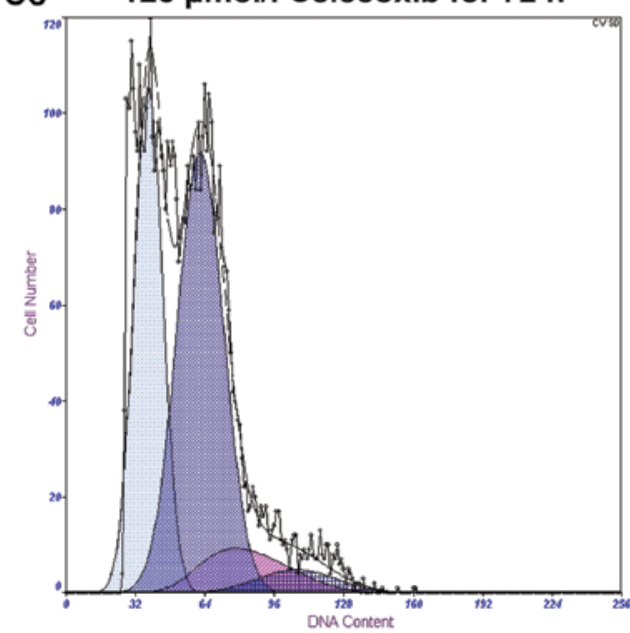

Cb

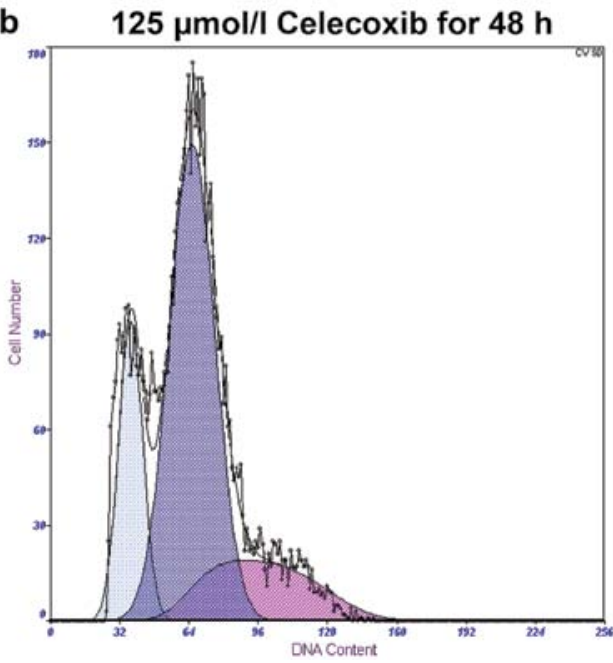

Cd

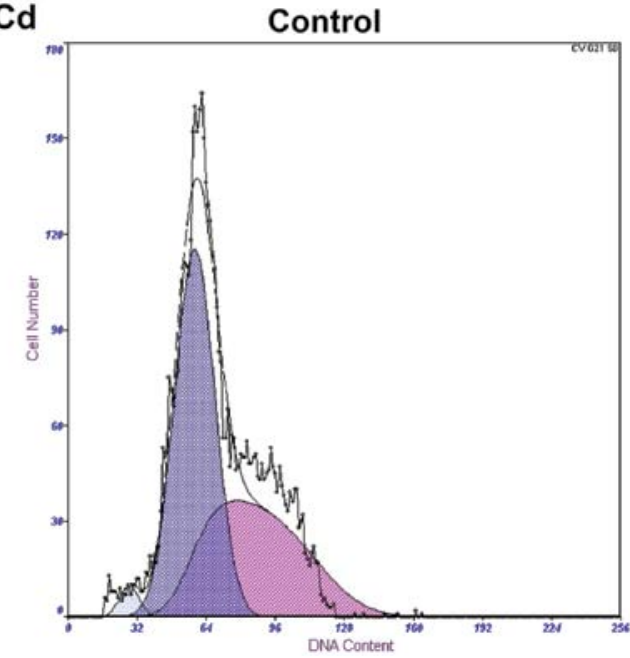

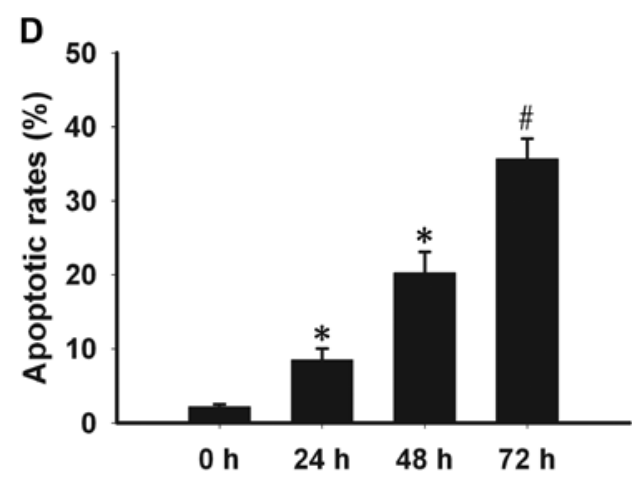

Figure 3. Continued. The apoptotic rates of SGC-7901 cells markedly increased in a time- and dose-dependent manner following treatment with $125 \mu$ mol/1 of celecoxib for $0,24,48$ and $72 \mathrm{~h}(\mathrm{C}$ and $\mathrm{D}) .{ }^{*} \mathrm{P}<0.05$ or ${ }^{\#} \mathrm{P}<0.01$ when compared with the control group.

cell proliferation, enabling tumor evasion of the host immune surveillance and promoting tumor invasion/metastasis $(5,17)$.

Multicellular organisms maintain their homeostasis through cell proliferation and PCD, with an imbalance possibly leading to the development of cancer. In this experiment, we found that the selective COX-2 inhibitor celecoxib induced apoptosis of SGC-7901 cells via reduced expression levels of COX-2, as obsreved by inhibited cell proliferation using MTT analysis and an increased number of apoptotic cells as detected by TUNEL and flow cytometry. Moreover, typical apoptotic changes were shown to include nuclear membrane shrinkage, nuclear chromatin condensation and apoptotic bodies using TEM to support the apoptotic effects of celecoxib.

Caspases are a type of protease associated with apoptosis and cytokine maturation, and are divided into initiator caspases, effector caspases and inflammatory mediators. Caspases are synthesized as relatively inactive zymogens and must undergo a process of activation during apoptosis. Caspase- 8 is the initiator of the Fas-Fas ligand (FasL) pathway, and usually exists in the form of procaspase-8. When FasL 

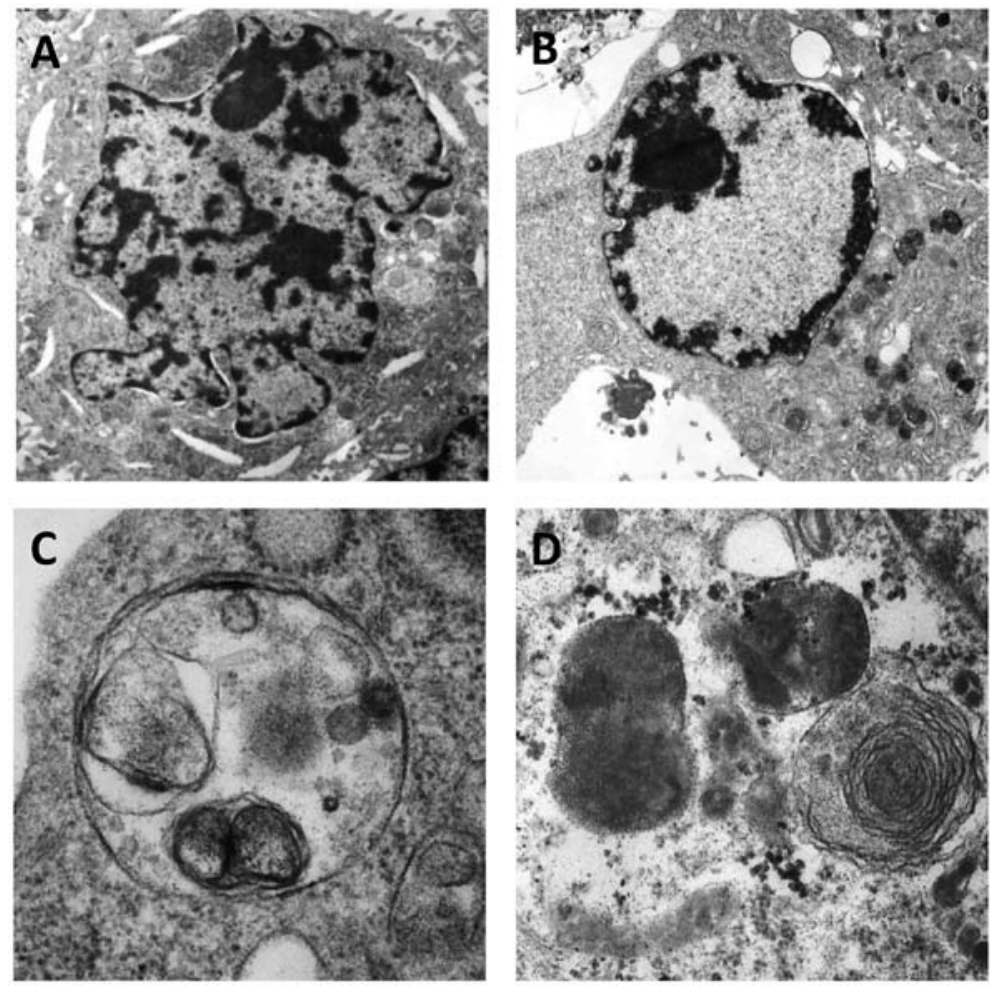

Figure 4. Ultrastructure changes of SGC-7901 cells following treatment with $125 \mu \mathrm{mol} / 1$ celecoxib for $72 \mathrm{~h}$. We observed nuclear membrane shrinkage and retraction in early apoptosis $(\mathrm{x} 5,000)(\mathrm{A})$, apoptotic body in late apoptosis $(\mathrm{x} 3,000)(\mathrm{B})$, and changes in autophagy: autophagic vacuolar and autophagosomes $(\mathrm{x} 40,000$ or $\mathrm{x} 30,000)(\mathrm{C}$ and $\mathrm{D})$ by TEM.
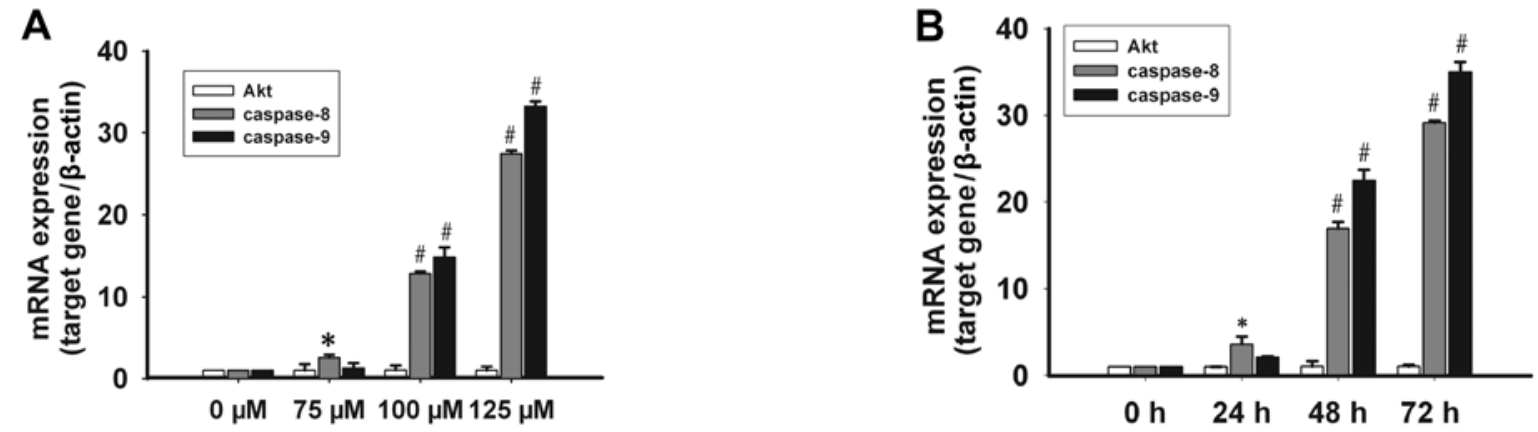

Figure 5. Akt, caspase-8 and -9 mRNA expression of SGC-7901 human gastric cancer cells following treatment with celecoxib at different doses and time-points with the first group including: the control, 75, 100 and $125 \mu \mathrm{mol} / 1$ celecoxib for $72 \mathrm{~h}$ (A) and group two including: the control, $125 \mu \mathrm{mol} / 1$ celecoxib for 24,48 and $72 \mathrm{~h}(\mathrm{~B}) .{ }^{*} \mathrm{P}<0.05$ or ${ }^{\prime \prime} \mathrm{P}<0.01$ relative to the control group from three independent experiments.

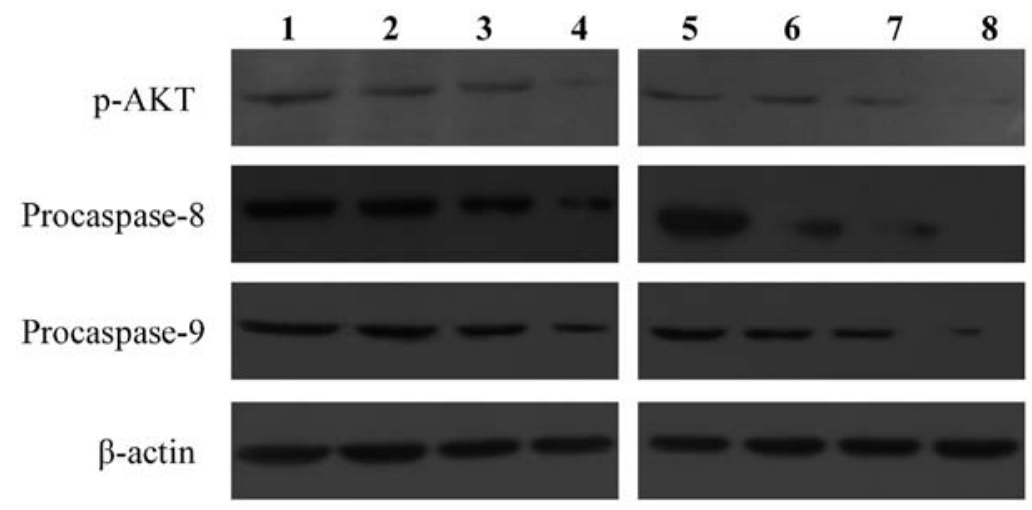

Figure 6. p-Akt, procaspase-8 and -9 protein expression in SGC-7901 human gastric cancer cells following treatment with celecoxib at different doses and time-points. SGC-7901 cells were treated with $0,75,100$ and $125 \mu \mathrm{mol} / 1$ celecoxib for $72 \mathrm{~h}$ (lanes 1-4) and treated with $125 \mu \mathrm{mol} / 1$ celecoxib for $0,24,48$ and $72 \mathrm{~h}$ (lanes 5-8). Procaspase-8, -9 and p-Akt protein expression were significantly lower than the control group in a time- and dose-dependent manner. Aliquots of protein extracts $(40 \mu \mathrm{g})$ were immunoblotted with the indicated antibodies. 
binds to the corresponding Fas receptor, the intracellular death effector domain (DED) of the Fas receptor attracts Fas associated with death domain protein (FADD) and recruits procaspase-8 to form a death-inducing signaling complex (DISC). Procaspase- 8 is then hydrolyzed to generate activated caspase- 8 , followed by the activation of procaspase- 3 and other effector caspases that eventually induce apoptosis (18). Caspase-9 is the initiator of the mitochondrial pathway, also known as procaspase-9, an inactive zymogen. The initiator caspase-9 is activated by the assembly of a multimeric complex (dubbed apoptosome) involving Apaf-1 and cytochrome $c$. Cleaved caspase- 9 and -3 are activated and these effector caspases degrade a large number of cell proteins, ultimately inducing cell apoptosis $(19,20)$. In this study, we found that celecoxib significantly increased caspase- 8 and -9 mRNA expression in a time- and dose-dependent manner in SGC-7901 cells, suggesting that celecoxib may activate caspase- 8 and -9 to initiated apoptosis through the death receptor and mitochondrial pathways, respectively.

Autophagy is a crucial component of the cellular stress adaptation response that maintains mammalian homeostasis (21). There are three different forms of autophagy that are commonly described: macroautophagy, microautophagy and chaperone-mediated autophagy. Macroautophagy is the predominant pathway occurring mainly to eradicate damaged organelles or unused proteins. Macroautophagy is mediated by a unique organelle, the autophagosome, which encloses long-lived proteins and portions of organelles for delivery to the lysosome $(22,23)$. Autophagy may play different roles in cancer occurrence and progression, while also potentially promoting or inhibiting cell proliferation at different stages of tumor growth (24). For example, autophagy plays a protective role in tumor cells via degradation of organelles under nutritional deficiency. Conversely, autophagy can also inhibit tumor growth via beclin 1, UVRAG, Bif and Atg. Findings of a recent study showed that berberine extracts promoted autophagy by activating beclin 1 expression and activated caspase- 9 to induce apoptosis in hepatoma cells (25). Plant lectin from Polygonatum cyrtonema induced apoptosis and autophagy by inhibiting the Ras/Raf and PI3K/Akt signaling pathways in murine fibrosarcoma cells (26). In this study, the selective COX-2 inhibitor celecoxib, not only generated morphological changes indicative of apoptosis, but also typical changes of autophagy to include cytoplasmic autophagic vacuoles and autophagosomes.

The molecular mechanism by which celecoxib induces apoptosis is not yet fully understood. The PI3K/Akt pathway widely presents in normal cells, but is abnormally activated in many malignant tumors (27-29). Akt, also known as protein kinase $\mathrm{B}(\mathrm{PKB})$, is a central component of the PI3K/Akt pathway, with Akt phosphoregulation impacting a variety of biological activities. In healthy and tumorigenic cells, Akt can be activated in an intracellular manner by hormones, growth factors, and extracellular matrix components (30). Akt regulates cell growth, survival and apoptosis through substrate phosphorylation, with Akt phosphoregulation observed at the Thr308 and Ser473 site, which are both required for activation. Akt is activated as follows: the activated PI3K produces a secondary messenger PIP3 at the plasma membrane, PIP3 then binds an inactive Akt inducing its shift from the cytoplasm to the plasma membrane where Ser124 and Thr450 are phosphorylated, making Akt undergo a conformational change exposing its Thr308 and Ser473 sites. Immediately, phosphoinositidedependent kinase 1 (PDK1) and phosphoinositide-dependent kinase 2 (PDK2), which are in close proximity to Akt, respectively catalyze the phosphorylation of the exposed Thr308 and Ser473 sites, resulting in the complete activation of Akt. This may trigger a phosphorylation cascade of downstream targets, ultimately impacting the regulation of cell growth and survival, proliferation and apoptosis, angiogenesis, cell migration and numerous biological processes (30-33).

In the present study, following celecoxib treatment in SGC-7901 cells, p-Akt, or activated Akt, was distinctly downregulated, leading to the upregulation of caspase- 8 and -9 mRNA expression and increased procaspase- 8 and -9 activation. Thus, we hypothesized that celecoxib inhibited the PI3K/Akt pathway by reducing the level of phosphorylation of Akt, which in turn activated the expression and activation of caspase- 8 and -9 , resulting in apoptosis through the death receptor and mitochondrial pathways in SGC-7901 cells. Notably, we found changes in the cell ultrastructure to include apoptosis and autophagy, suggesting that celecoxib simultaneously induced apoptosis and autophagy, which is consistent with results of previous studies $(5,13))$. Autophagy is an evolutionarily conserved process that occurs during the growth and development process in many animals, but its specific mechanism of PCD is unclear. Autophagy and apoptosis could coadjust through p53 (35), PI3K/Akt (36) and Bcl-2-beclin 1 (37). Thus, celecoxib may impact both apoptosis and autophagy via the PI3K/Akt signaling pathway in the SGC-7901 gastric cancer cells. The results of this study provide a new theoretical foundation for the antitumor mechanisms of celecoxib and offers new targets for cancer therapy, although these findings should be verified in future investigations.

\section{Acknowledgements}

This study was supported by a grant from the National Science Foundation of China (no. 81172366). We would like to thank LetPub for its linguistic assistance during the preparation of this manuscript.

\section{References}

1. Saukkonen K, Rintahaka J, Sivula A, et al: Cyclooxygenase-2 and gastric carcinogenesis. APMIS 111: 915-925, 2003.

2. Jones DA, Carlton DP, McIntyre TM, Zimmerman GA and Prescott SM: Molecular cloning of human prostaglandin endoperoxide synthase type II and demonstration of expression in response to cytokines. J Biol Chem 268: 9049-9054, 1993.

3. Sarkar FH, Adsule S, Li Y and Padhye S: Back to the future: COX-2 inhibitors for chemoprevention and cancer therapy. Mini Rev Med Chem 7: 599-608, 2007.

4. Duan L, Wu AH, Sullivan-Halley J and Bernstein L: Nonsteroidal anti-inflammatory drugs and risk of esophageal and gastric adenocarcinomas in Los Angeles County. Cancer Epidemiol Biomarkers Prev 17: 126-134, 2008.

5. Fu SL, Wu YL, Zhang YP, Qiao MM and Chen Y: Anti-cancer effects of COX-2 inhibitors and their correlation with angiogenesis and invasion in gastric cancer. World J Gastroenterol 10: 1971-1974, 2004

6. Lo AC, Woo TT, Wong RL and Wong D: Apoptosis and other cell death mechanisms after retinal detachment: implications for photoreceptor rescue. Ophthalmologica 226 (Suppl 1): 10-17, 2011. 
7. Su M, Mei Y and Sinha S: Role of the crosstalk between autophagy and apoptosis in cancer. J Oncol 2013: 102735, 2013.

8. Qadri SS, Wang JH, Coffey JC, et al: Surgically induced accelerated local and distant tumor growth is significantly attenuated by selective COX-2 inhibition. Ann Thorac Surg 79: 990-995, 2005

9. Grösch S, Maier TJ, Schiffmann S and Geisslinger G: Cyclooxygenase-2 (COX-2)-independent anticarcinogenic effects of selective COX-2 inhibitors. J Natl Cancer Inst 98: 736-747, 2006.

10. Baek JY, Hur W, Wang JS, Bae SH and Yoon SK: Selective COX-2 inhibitor, NS-398, suppresses cellular proliferation in human hepatocellular carcinoma cell lines via cell cycle arrest. World J Gastroenterol 13: 1175-1181, 2007.

11. Jendrossek V: Targeting apoptosis pathways by celecoxib in cancer. Cancer Lett 332: 313-324, 2013.

12. Fan XM, Jiang XH, Gu Q, et al: Inhibition of Akt/PKB by a COX-2 inhibitor induces apoptosis in gastric cancer cells Digestion 73: 75-83, 2006.

13. Kim N, Kim CH, Ahn DW, et al: Anti-gastric cancer effects of Celecoxib, a selective COX-2 inhibitor, through inhibition of Ak signaling. J Gastroenterol Hepatol 24: 480-487, 2009.

14. Patru CL, Surlin V, Georgescu I and Patru E: Current issues in gastric cancer epidemiology. Rev Med Chir Soc Med Nat Iasi 117: 199-204, 2013

15. Futagami S, Suzuki K, Hiratsuka T, et al: Chemopreventive effect of Celecoxib in gastric cancer. Inflammopharmacology 15 $1-4,2007$.

16. Willoughby DA, Moore AR and Colville-Nash PR: COX-1, COX-2, and COX-3 and the future treatment of chronic inflammatory disease. Lancet 355: 646-648, 2000.

17. Greenhough A, Smartt HJ, Moore AE, et al: The COX-2/PGE2 pathway: key roles in the hallmarks of cancer and adaptation to the tumour microenvironment. Carcinogenesis 30: 377-386, 2009.

18. Liu Y and Liu BA: Enhanced proliferation, invasion, and epithelial-mesenchymal transition of nicotine-promoted gastric cancer by periostin. World J Gastroenterol 17: 2674-2680, 2011.

19. Fulda S: Caspase-8 in cancer biology and therapy. Cancer Lett 281: 128-133, 2009.

20. Würstle ML, Laussmann MA and Rehm M: The central role of initiator caspase-9 in apoptosis signal transduction and the regulation of its activation and activity on the apoptosome. Exp Cell Res 318: 1213-1220, 2012.

21. Allan LA and Clarke PR: Apoptosis and autophagy: Regulation of caspase-9 by phosphorylation. FEBS J 276: 6063-6073, 2009

22. White E, Karp C, Strohecker AM, Guo Y and Mathew R: Role of autophagy in suppression of inflammation and cancer. Curr Opin Cell Biol 22: 212-217, 2010.

23. Lorin S, Hamaï A, Mehrpour M and Codogno P: Autophagy regulation and its role in cancer. Semin Cancer Biol 23: 361-379, 2013.
24. White E: Deconvoluting the context-dependent role for autophagy in cancer. Nat Rev Cancer 12: 401-410, 2012.

25. Helgason GV, Holyoake TL and Ryan KM: Role of autophagy in cancer prevention, development and therapy. Essays Biochem 55: 133-151, 2013.

26. Xie BS, Zhao HC, Yao SK, et al: Autophagy inhibition enhances etoposide-induced cell death in human hepatoma G2 cells. Int J Mol Med 27: 599-606, 2011.

27. Liu B, Wu JM, Li J, et al: Polygonatum cyrtonema lectin induces murine fibrosarcoma L929 cell apoptosis and autophagy via blocking Ras-Raf and PI3K-Akt signaling pathways. Biochimie 92: 1934-1938, 2010.

28. Ye B, Jiang LL, Xu HT, Zhou DW and Li ZS: Expression of PI3K/AKT pathway in gastric cancer and its blockade suppresses tumor growth and metastasis. Int J Immunopathol Pharmacol 25: 627-636, 2012.

29. Lin X, Zhang X, Wang Q, et al: Perifosine downregulates MDR1 gene expression and reverses multidrug-resistant phenotype by inhibiting PI3K/Akt/NF-kappaB signaling pathway in a human breast cancer cell line. Neoplasma 59: 248-256, 2012.

30. Kang XH, Xu ZY, Gong YB, et al: Bufalin reverses HGF-induced resistance to EGFR-TKIs in EGFR mutant lung cancer cells via blockage of Met/PI3k/Akt pathway and induction of apoptosis. Evid Based Complement Alternat Med 2013: 243859, 2013

31. Chang F, Lee JT, Navolanic PM, et al: Involvement of PI3K/Akt pathway in cell cycle progression, apoptosis, and neoplastic transformation: a target for cancer chemotherapy. Leukemia 17: 590-603, 2003

32. Song G, Ouyang G and Bao S: The activation of Akt/PKB signaling pathway and cell survival. J Cell Mol Med 9: 59-71, 2005.

33. Falasca M: PI3K/Akt signalling pathway specific inhibitors: a novel strategy to sensitize cancer cells to anti-cancer drugs. Curr Pharm Des 16: 1410-1416, 2010.

34. Garcia-Echeverria $C$ and Sellers WR: Drug discovery approaches targeting the PI3K/Akt pathway in cancer. Oncogene 27: 5511-5526, 2008.

35. Liu J, Lin Y, Yang H, Deng Q, Chen and He J: The expression of p33(ING1), p53, and autophagy-related gene Beclin1 in patients with non-small cell lung cancer. Tumor Biol 32: 1113-1121, 2011.

36. Cheng Y, Ren X, Zhang Y, et al: eEF-2 kinase dictates cross-talk between autophagy and apoptosis induced by Akt inhibition, thereby modulating cytotoxicity of novel Akt inhibitor MK-2206. Cancer Res 71: 2654-2663, 2011.

37. Djavaheri-Mergny M, Maiuri MC and Kroemer G: Cross talk between apoptosis and autophagy by caspase-mediated cleavage of Beclin 1. Oncogene 29: 1717-1719, 2010. 